\title{
O PAPEL DA VEGETAÇÃO NO CONTROLE DOS VENTOS PARA O CONFORTO TÉRMICO
}

\author{
THE VEGETATION ROLE IN THE CONTROL OF \\ WINDS TO THERMAL COMFORT
}

\author{
Helena Cristina Padovani Zanlorenzi \\ Arquiteta, doutoranda em Tecnologia da Arquitetura na Faculdade de Arquitetura e Urbanismo da \\ Universidade de São Paulo, São Paulo - SP. \\ E-mail: helenapz@usp.br \\ Demóstenes Ferreira da Silva Filho \\ Engenheiro Agrônomo, Professor Doutor em Ciências Florestais na Escola Superior de Agricultura \\ Luiz de Queiroz da Universidade de São Paulo, Piracicaba - SP. \\ E-mail: dfilho@usp.br
}

\begin{abstract}
RESUMO
Entender o clima dos espaços urbanos em suas diversas conformações é objeto de grande interesse para a melhoria da qualidade de vida de seus usuários. O presente estudo é parte integrante da dissertação de mestrado que teve por objetivo avaliar elementos de vegetação como barreira aos ventos visando o conforto térmico em espaços abertos. O procedimento utilizado foi quantificar a interferência de elementos vegetais na passagem dos ventos, na altura dos pedestres, a partir de configurações de vegetação pré-estabelecidas. O cenário eleito para este estudo foi a área externa do Campus da Universidade Metodista de Piracicaba (UNIMEP), localizado no bairro Taquaral em Piracicaba, SP. Foram estudadas três espécies dispostas em arranjos de barreira aos ventos: Jasminum mesnyi Hance, Pseudosasa japonica (Steud.) Makino e Pinus caribaea Morelet. As variáveis microclimáticas medidas foram temperatura do ar, umidade relativa do ar e velocidade dos ventos, em três posições distintas por espécie: em um campo aberto próximo, antes e depois da barreira. O período de coleta de dados foi das 9 às 21 horas, em intervalos de 3 a 5 minutos, durante três dias por espécie, nos meses de agosto e setembro de 2014. Foi feita a medição do LAI (Índice de Área Foliar) das barreiras, para análise da viabilidade de adoção do LAI como parâmetro na previsão de resultados, o que permitiria sua aplicabilidade a outras espé-
\end{abstract}


cies. Os resultados obtidos indicam uma tendência favorável a este princípio, porém estudos com maior intensidade amostral são necessários para obtenção desta correlação. Outras aplicações podem ser beneficiadas com esta linha de estudo, como a previsão do risco de queda de árvores.

Palavras-chave: Silvicultura urbana; Clima urbano; Conforto térmico; Barreira aos ventos; LAl

\section{ABSTRACT}

Understanding the climate of urban areas in its various conformations is an object of great interest for the improvement of the life quality of its users. This study is part of the Master's Degree thesis that aimed to evaluate vegetation elements as a barrier to winds, targeting the thermal comfort in open spaces. The used procedure was to quantify the interference of vegetation elements in the wind flows, at pedestrians' height, from pre-established vegetation configurations. The scenario chosen for this study was the external area of the Methodist University of Piracicaba (UNIMEP) Campus, in Taquaral District in Piracicaba City, SP. A combination of three species arranged as wind barrier were studied: Jasminum mesnyi Hance, Pseudosasa japonica (Steud.) Makino and Pinus caribaea Morelet. The measured microclimate variables were: air temperature, relative air humidity and wind speed, in three distinct positions per species: in an open field nearby, in front and behind the barrier. The data collection period was from 9 a.m. to 9 p.m., in intervals of 3 to 5 minutes, for three days each species, during August and September 2014. It was taken the LAI (Leaf Area Index) measurement of the barriers, to analyze the feasibility of adopting it as a parameter to predict results, what would allow its applicability to other species. The results indicated a favorable trend towards this principle, but studies with more sampling intensity are necessary to obtain this correlation. Other uses may have benefits from this line of study, as predicting the risk of falling trees, for instance.

Keywords: Urban forestry; Urban climate; Thermal comfort; Windbreaks; LAI 


\section{INTRODUÇÃO}

O vento não é um fenômeno constante: varia instantaneamente em direção e intensidade. Trata-se de um dos fatores mais importantes nas condições de conforto humano em espaços abertos, no entanto seu comportamento é difícil de prever e controlar por sofrer influências de um grande número de variáveis globais, regionais e locais (NIKOLOPOULOU, 2004). Os estudos de conforto térmico que envolvem a avaliação e a quantificação dos ventos são complexos diante da variabilidade instantânea que apresentam, porém alguns parâmetros podem ser estabelecidos. A maior parte das pesquisas já realizadas relativas a ventos em áreas externas são empíricas.

A efetividade de uma barreira arbórea depende de sua posição em relação ao fluxo do vento, da porosidade da barreira, da altura das árvores e da distância do ponto a proteger; a porosidade por sua vez depende do tipo de árvore, da distância entre as árvores e da sobreposição entre as fileiras (ERELL, 2011). Estudos teóricos e experimentais indicam que uma barreira porosa é mais efetiva que uma barreira sólida.

Santiago et al. (2007) realizaram experimentos em túnel de vento com barreiras de diferentes porosidades entre 0 e $50 \%$, com o objetivo de determinar a porosidade ótima para a eficiência de uma barreira isolada; o melhor resultado foi obtido com uma barreira de $35 \%$ de porosidade, sempre a favor do vento (WU et al., 2013), que sugerem a porosidade ideal entre 30 e $40 \%$.

O objetivo geral deste estudo foi avaliar o comportamento de elementos vegetais como barreira aos ventos e introduzir a variável LAl, facilmente mensurável, como uma medida a ser explorada nos estudos de barreiras vegetais em áreas urbanas.

\section{MATERIAIS E MÉTODOS}

A cidade de Piracicaba está localizada na região centro-leste do Estado de São Paulo (2243'30"S; 47³8'56'W); o clima local é do tipo Cwa (classificação de Köppen-Geiger), com temperaturas máximas e mínimas médias anuais de $28,2^{\circ} \mathrm{C}$ e $15,1^{\circ} \mathrm{C}$ respectivamente, e precipitação média anual de $1.274 \mathrm{~mm}$ (LEB - ESALQ - USP). 


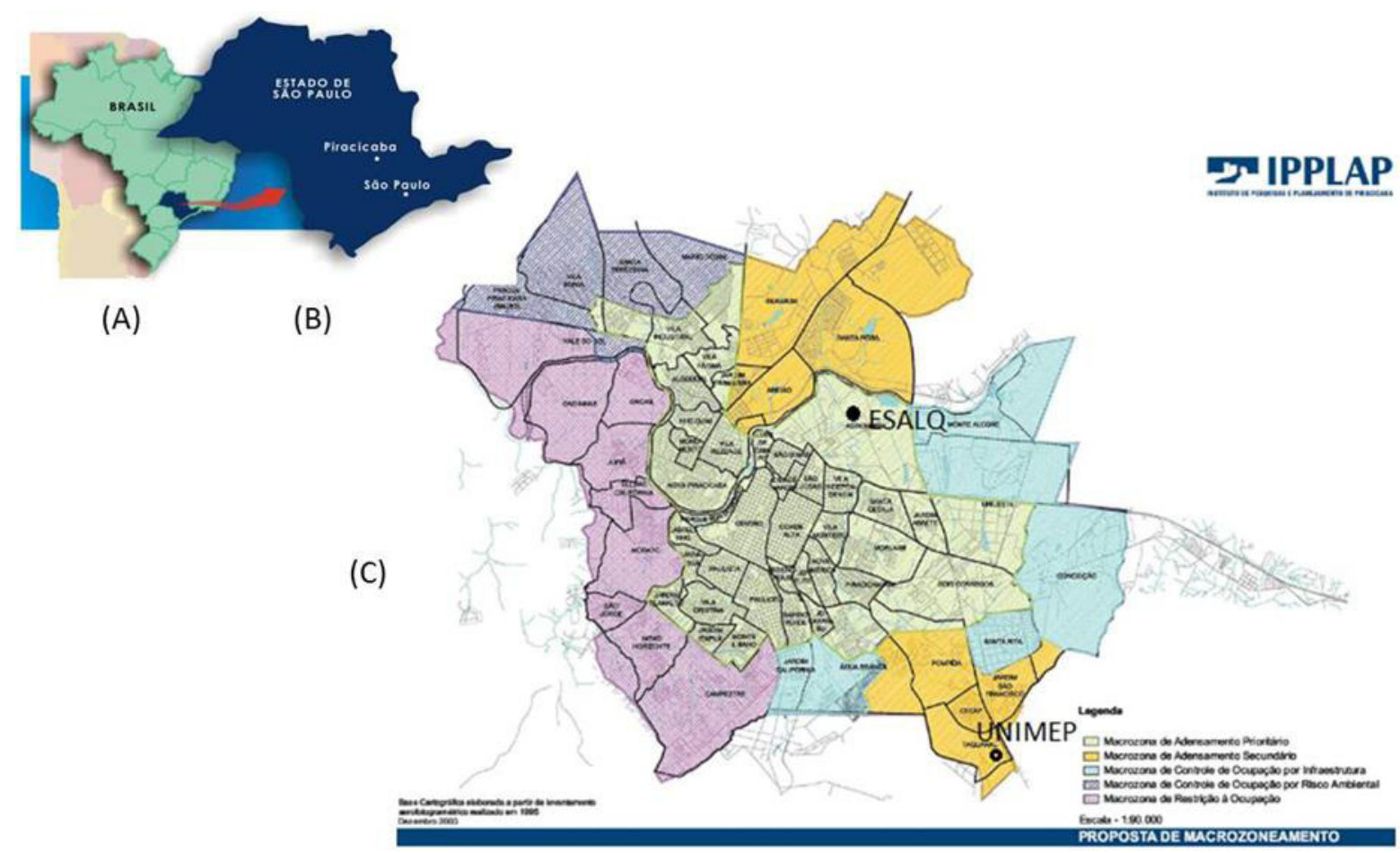

Figura 1 - Situação da área de estudo: (A) a localização do Estado de São Paulo no Brasil; (B) a cidade de Piracicaba no centro-leste do Estado de São Paulo; (C) o perímetro urbano com localização da área de estudo. Fonte: Google imagens
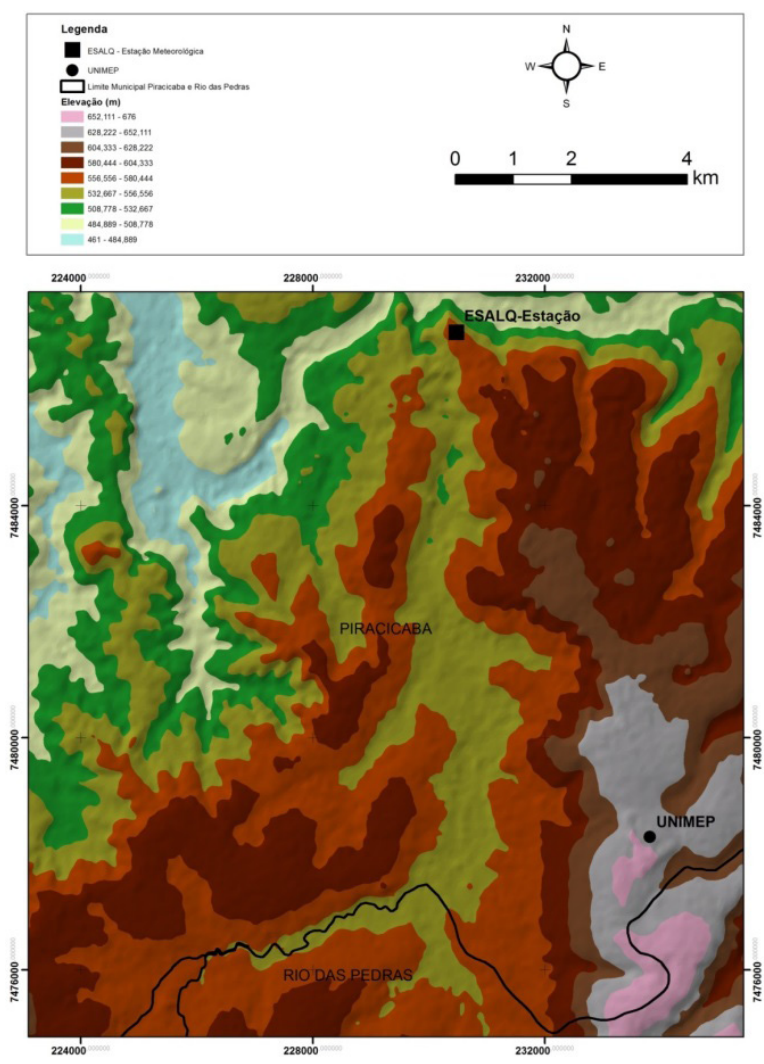

Segundo Barretto (2006), o município de Piracicaba apresenta uma depressão na parte central de seu território que segue o sentido leste-oeste do curso do Rio Piracicaba. Os pontos de interesse estão a uma altitude da ordem de $650 \mathrm{~m}$ na Unimep (local de coleta dos dados em campo) e de $570 \mathrm{~m}$ na Esalq (local da estação meteorológica utilizada como referência), conforme indicado na Figura 2.

Figura 2 - Caracterização topográfica da área de estudo. Fonte: TOPODATA - Variáveis geomorfométricas derivadas de dados SRTM (Shuttle Radar Topographic Mission), INPE, 2008 
Os levantamentos de campo foram realizados no Campus Taquaral da UNIMEP, que ocupa área de mais de 360 mil m² $^{2}$ com entorno de baixa ocupação territorial e distante da área adensada da cidade (Figura 3). Há queixas dos usuários por desconforto nos dias frios devido ao excesso de ventos, embora seja uma região com clima predominantemente quente ao longo do ano.

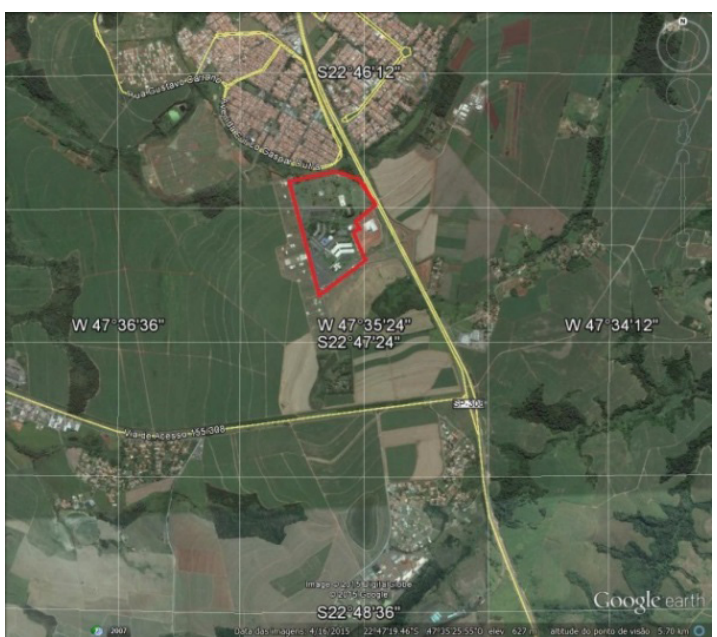

(a)

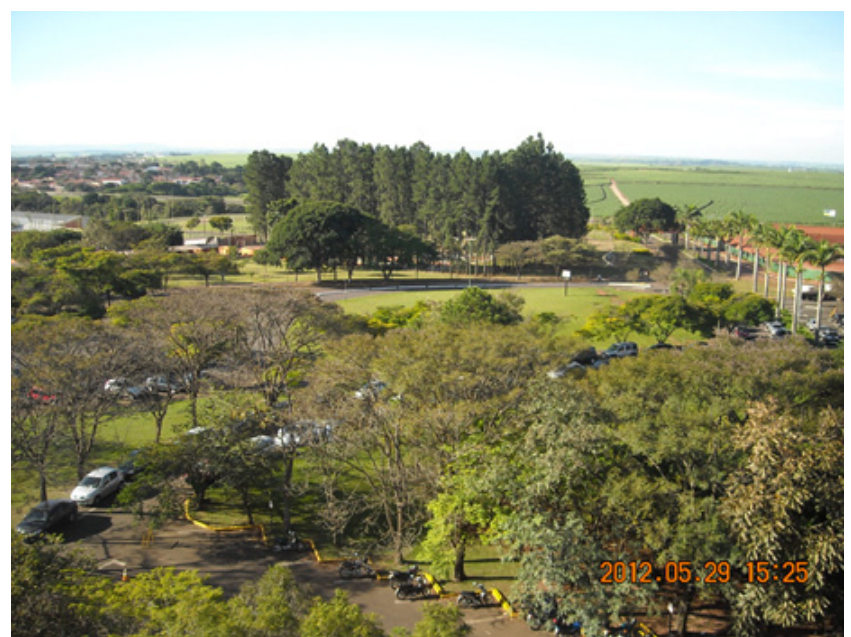

(b)

Figura 3 - UNIMEP Campus Taquaral e entorno: (a) em destaque e (b) foto do local. Fontes: (a) Google Earth, imagem de 16 abril 2015 e (b) da autora

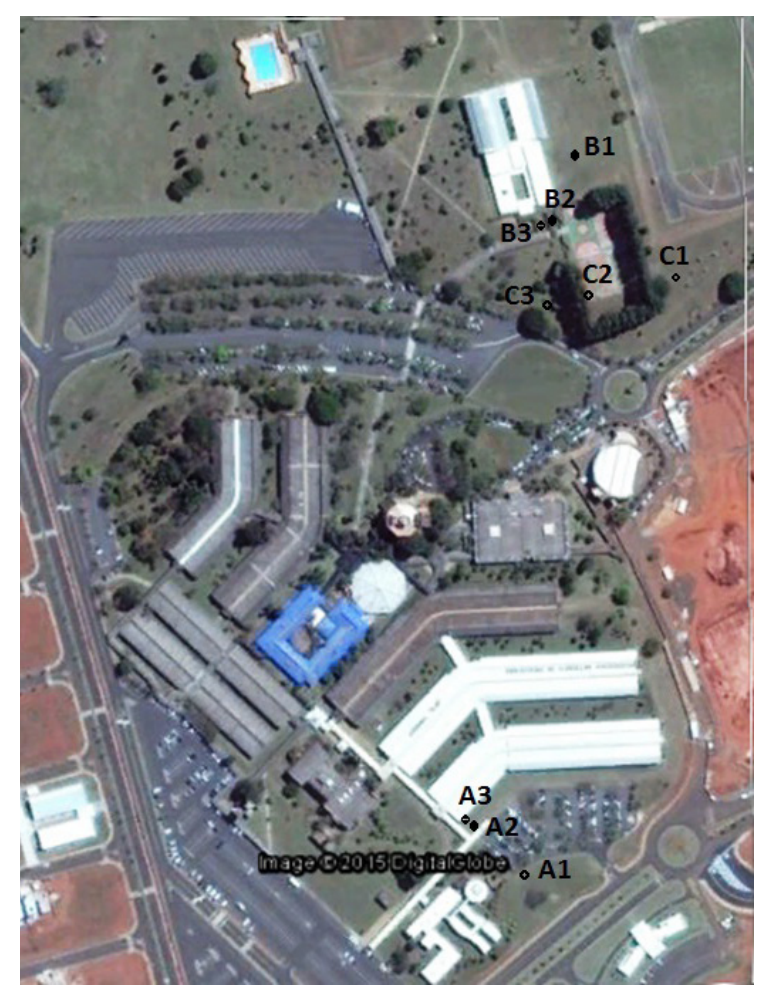

Foram estudadas três diferentes espécies arbóreas dispostas como barreira aos ventos: Jasminum mesnyi Hance (Jasmim), Pseudosasa japonica (Steud.), Makino (Bambu) e Pinus caribaea Morelet (Pinus). Na figura ao lado estão localizados os locais de medição A (Jasmim), B (Bambu) e C (Pinus), cada um contendo três pontos: Ponto 1 - em campo aberto próximo; Ponto 2 - antes da barreira; Ponto 3 - depois da barreira.

Figura 4 - UNIMEP Taquaral - Pontos de medição: (A) Jasmim, (B) Bambu e (C) Pinus, sendo 3 pontos por vegetação: (1) em campo aberto, (2) antes da barreira e (3) após a barreira. Fonte: Google Earth, imagem de 09 ago. 2014, data de coleta de dados desta pesquisa 
Cada espécie estudada teve os dados do monitoramento microclimático colhidos durante três dias, das 9 às 21 horas, sendo Temperatura do $\operatorname{ar}\left({ }^{\circ} \mathrm{C}\right)$ e Umidade do $\operatorname{ar}(\%)$ a cada 5 minutos e Velocidade do ar ( $\mathrm{m} / \mathrm{s})$ a cada 3 minutos, em agosto e setembro de 2014. Os equipamentos foram fixados em tripés a $1,5 \mathrm{~m}$ de altura, sendo cada estação de medição composta dos seguintes equipamentos devidamente calibrados:

- Um medidor de temperatura e umidade relativa do ar, modelo Logger Type ThermaData, protegido da radiação direta em caixa ventilada, registrando a cada 5 minutos;

- Um anemômetro / termômetro digital Testo 445 com sensor registrando a cada 3 minutos; registrador alimentado por bateria externa e protegido por caixa de isopor.
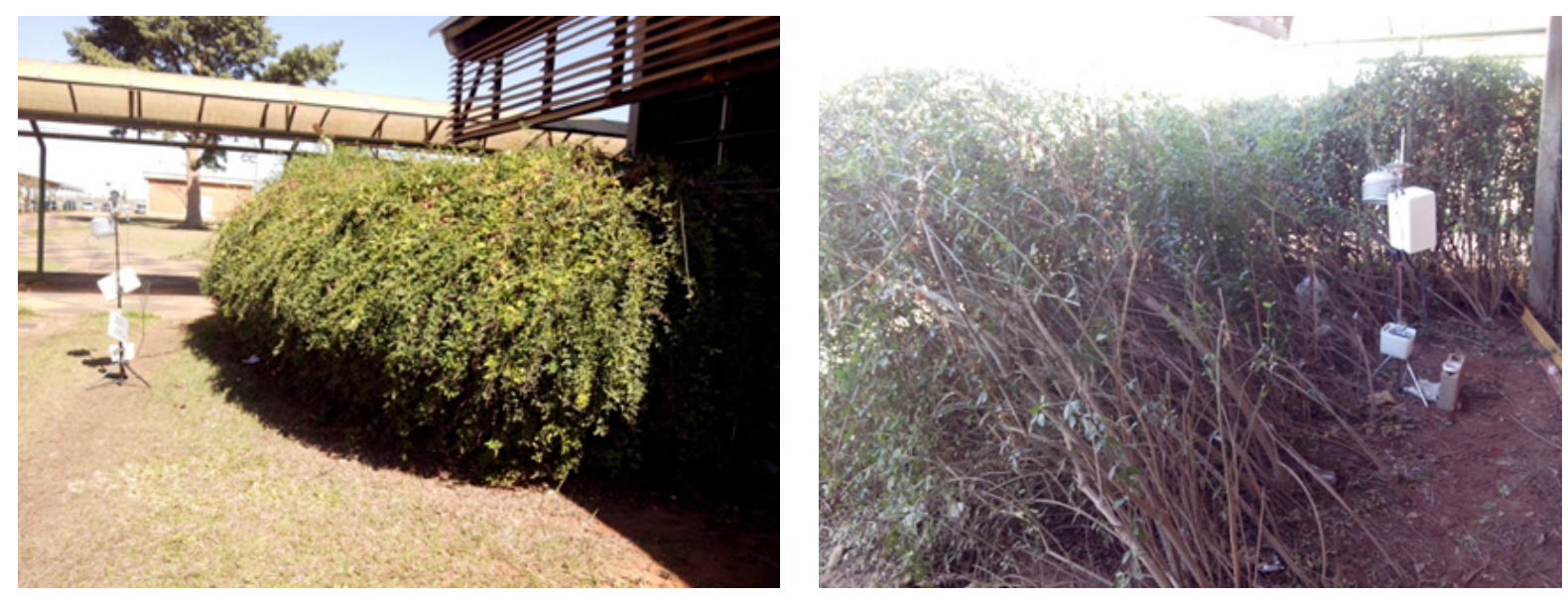

Figura 5 - JASMIM: (a) Ponto 2 (antes da barreira) e (b) Ponto 3 (depois da barreira) Fonte: da autora, imagens de 07 ago. 2014
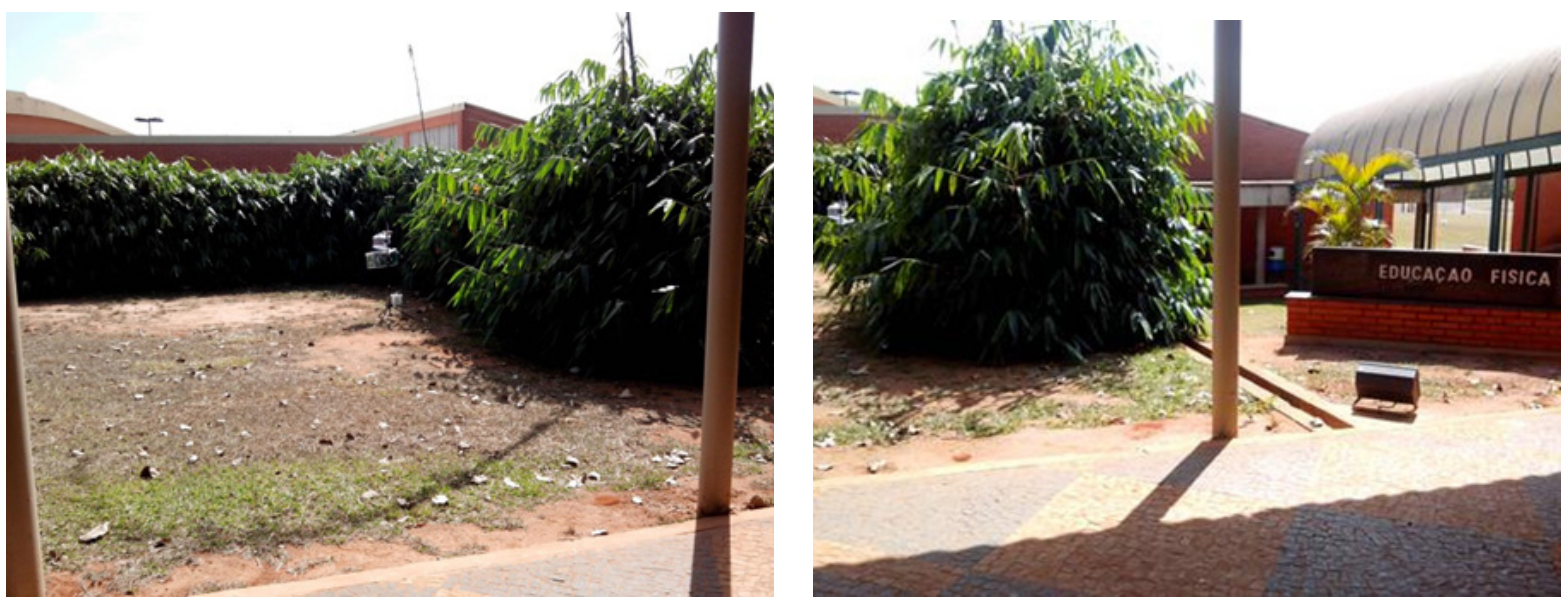

Figura 6 - BAMBU: (a) Ponto 3 e (b) Pontos 2 e 3. Fonte: da autora, imagens de 11 ago. 2014 

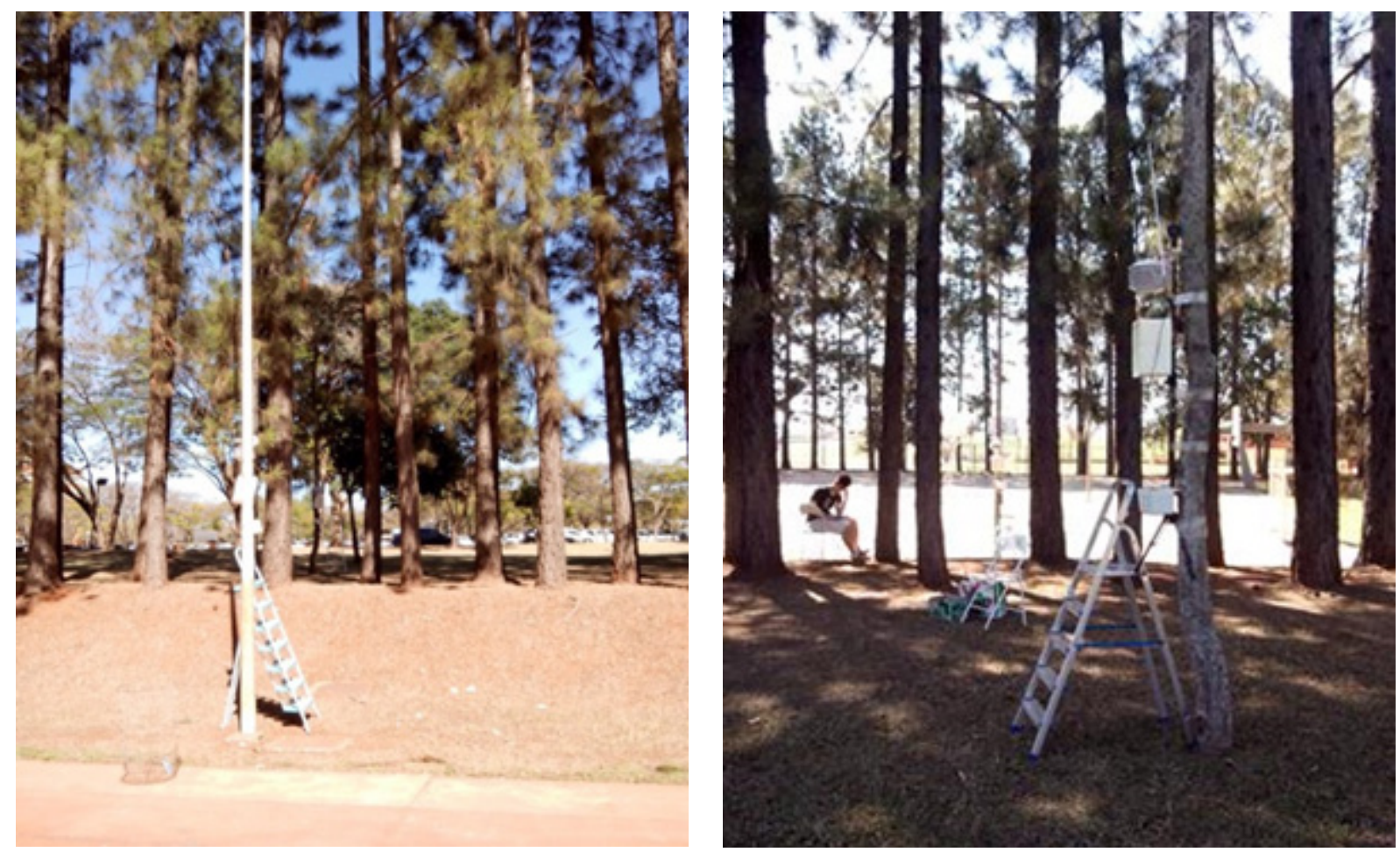

Figura 7 - PINUS: (a) Ponto 2 (antes da barreira) e (b) Ponto 3 (após a barreira) Fonte: da autora, imagens de 06 set. 2014

\section{RESULTADOS E DISCUSSÃO}

Para quantificar a atenuação da velocidade do vento pela vegetação, faz-se necessário considerar sempre a diferença entre o maior e o menor valor de velocidade do vento, entre os valores 'antes da barreira' e 'depois da barreira'. Para manter a coerência nos resultados, os dados foram corrigidos quando houve inversão do sentido do vento, uma vez que o foco principal desta pesquisa foi conhecer valores de atenuação das barreiras e não os valores absolutos das velocidades do vento próximo a elas.

$\mathrm{Na}$ comparação entre os elementos arbóreos quanto à atenuação aos ventos, cada dia medido por vegetação foi considerado como uma repetição. Foi utilizado o teste não paramétrico de Kruskal-Wallis para comparações das áreas analisadas; seus resultados não apresentaram diferenças significativas por ausência de intensidade amostral. Para localização das diferenças foi aplicado o teste de Tukey, p-valor $<0.05$. No teste de Tukey, a diferença entre os grupos existe quando as diferenças entre as médias forem maiores que o valor da diferença mínima significante (Dms). Fazendo-se a análise das velocidades dos ventos por vegetação, foram encontradas seguintes variações significativas: 


\section{- BAMBU}

Na velocidade média do vento houve diferença significativa entre os 3 pontos de medição. Na velocidade máxima e na amplitude do vento houve diferença significativa entre os Pontos 1 e 2.

Tabela 1 - Resultados - BAMBU

\begin{tabular}{lllllll}
\hline Dado & $\mathbf{R}^{2}$ & Coef. Variância & Média & Valor de $\mathbf{F}$ & $\operatorname{Pr}>\mathbf{F}$ & Dms $^{(\mathrm{a})}$ \\
\hline V média & 0.983826 & 5.927734 & 0.733643 & 182.48 & $<.0001$ & 0.0787 \\
\hline V máxima & 0.859133 & 39.46810 & 2.324444 & 18.30 & 0.0028 & 0.6695 \\
\hline Amplitude & 0.831170 & 49.44479 & 2.232222 & 14.77 & 0.0048 & 0.7699 \\
\hline
\end{tabular}

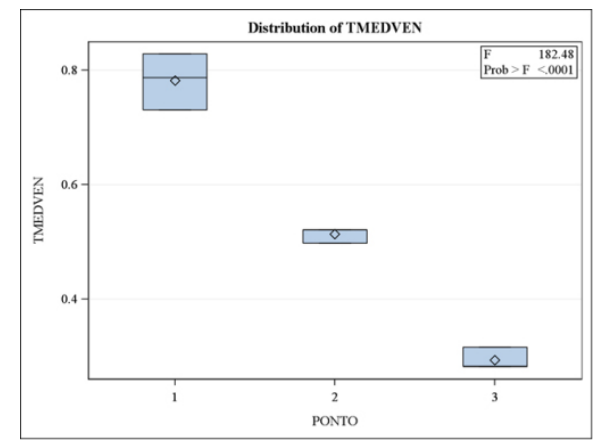

\begin{tabular}{clc}
\hline \multicolumn{1}{l}{ V média } & \\
\hline Teste de Tukey & Média & Ponto \\
\hline $\mathrm{A}$ & 0.78242 & 1 \\
\hline $\mathrm{B}$ & 0.51355 & 2 \\
\hline $\mathrm{C}$ & 0.29338 & 3 \\
\hline V máxima & &
\end{tabular}

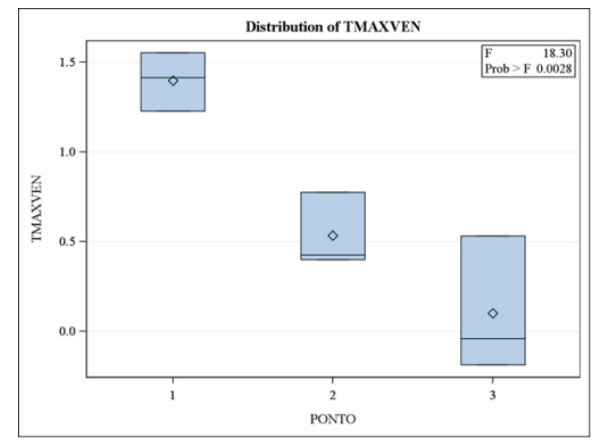

\begin{tabular}{ccc}
\hline Teste de Tukey & Média & Ponto \\
\hline A & 1.3973 & 1 \\
\hline B & 0.5329 & 2 \\
\hline B & 0.1012 & 3 \\
\hline
\end{tabular}

Amplitude

\begin{tabular}{ccc}
\hline Teste de Tukey & Média & Ponto \\
\hline A & 1.3715 & 1 \\
\hline B & 0.4541 & 2 \\
\hline B & 0.0390 & 3 \\
\hline
\end{tabular}

(a) Dms = diferença mínima significante $=$ médias seguidas da mesma letra não diferem entre si pelo teste de Tukey a $5 \%$ de probabilidade 
- JASMIM

Na velocidade máxima do vento e na amplitude, houve diferença significativa entre os 3 pontos de medição.

Tabela 2 - Resultados - JASMIM

\begin{tabular}{lllllll}
\hline Dado & $\mathbf{R}^{2}$ & Coef. Variância & Média & Valor de $\mathbf{F}$ & $\operatorname{Pr}>\mathbf{F}$ & dms \\
\hline V máxima & 0.897176 & 11.70339 & 3.328889 & 26.18 & 0.0011 & 0.3357 \\
\hline Amplitude & 0.914759 & 10.69442 & 3.237778 & 32.19 & 0.0006 & 0.2998 \\
\hline
\end{tabular}
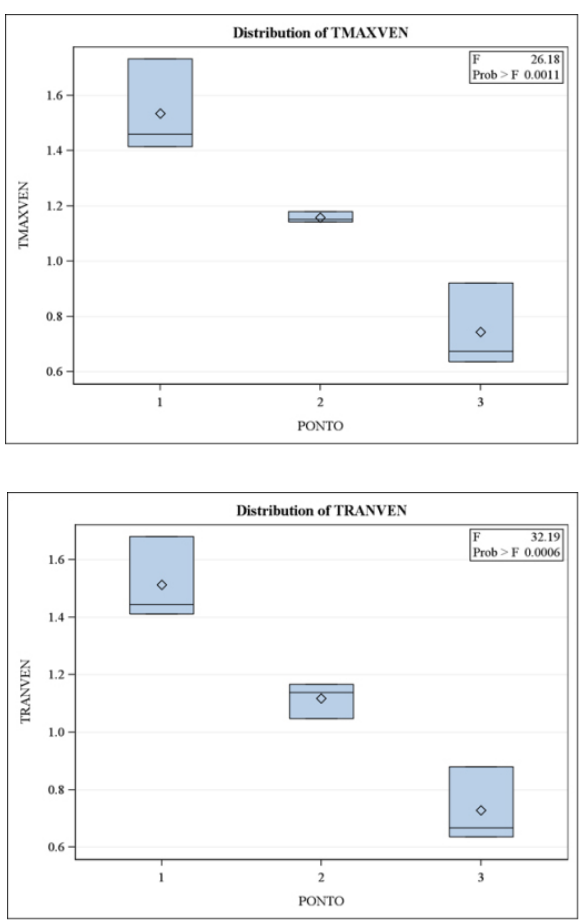

\begin{tabular}{ccc}
\hline V máxima & & \\
\hline Teste de Tukey & Média & Ponto \\
\hline A & 1.5346 & 1 \\
\hline B & 1.1568 & 2 \\
\hline C & 0.7433 & 3 \\
\hline
\end{tabular}

Amplitude

\begin{tabular}{ccc}
\hline Teste de Tukey & Média & Ponto \\
\hline A & 1.51213 & 1 \\
\hline B & 1.11714 & 2 \\
\hline C & 0.72801 & 3 \\
\hline
\end{tabular}

\section{- PINUS}

Na amplitude, houve diferença significativa entre os Pontos 1 e 3.

Tabela 3 - Resultados - PINUS

\begin{tabular}{lllllll}
\hline Dado & $\mathbf{R}^{2}$ & Coef. Variância & Média & Valor de F & Pr $>$ F & dms \\
\hline Amplitude & 0.737096 & 15.18341 & 3.312000 & 8.41 & 0.0182 & 0.478 \\
\hline
\end{tabular}




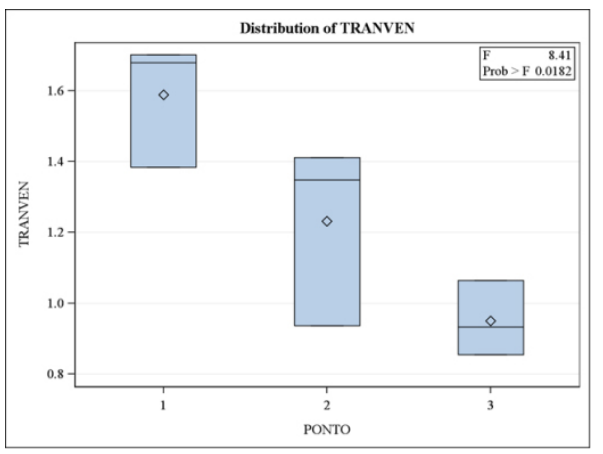

\begin{tabular}{l}
\multicolumn{2}{l}{ Amplitude } \\
\begin{tabular}{c|ccc}
\multicolumn{2}{l}{ Teste de Tukey } & Média & Ponto \\
\hline & A & 1.5880 & 1 \\
\hline B & A & 1.2317 & 2 \\
\hline B & & 0.9504 & 3 \\
\hline
\end{tabular}
\end{tabular}

Fazendo-se a análise da variância da velocidade do vento por vegetação, foram encontradas diferenças significativas entre os 3 pontos de medição no Bambu para velocidade média, e no Jasmim para velocidade máxima e para amplitude. No Pinus houve variação significativa apenas entre os Pontos 1 e 3 na amplitude, indicando menor eficiência deste elemento na barragem aos ventos em relação às outras vegetações estudadas.

Outras análises foram feitas com o software Minitab Versão 17, cujos resultados estão a seguir. Na Figura 8 as intensidades do vento estão agrupadas por vegetação, nos 3 pontos medidos. Pode-se constatar que o Bambu apresenta mais observações de baixas velocidades do vento.

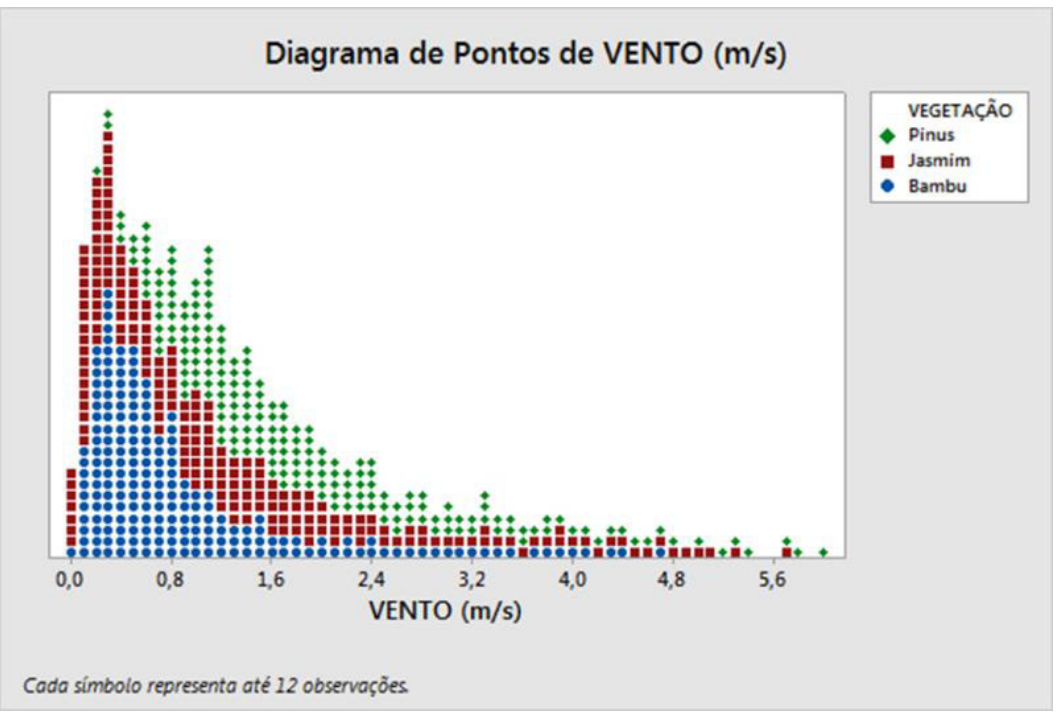

Figura 8 - Intensidades do vento por vegetação

A Figura 9 a seguir apresenta as observações resultantes por planta e por ponto medido. É possível verificar que entre os Pontos 2 (antes da barreira) e 3 (depois da barreira), o Bambu apresenta maior diferença nas velocidades do vento. 


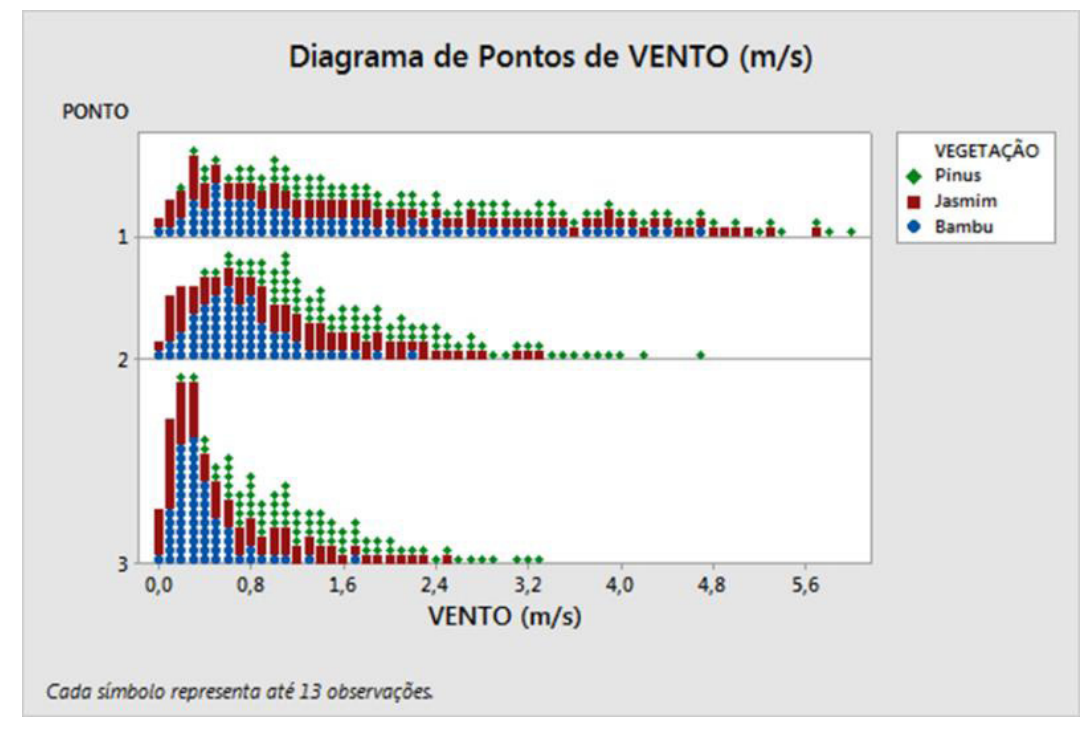

Figura 9 - Intensidades do vento por vegetação e por ponto medido

Nas Figuras 10 a 12 observa-se os ventos resultantes nas medições in loco, por vegetação, ao longo dos 3 dias, em sequência. As 3 curvas de cada gráfico correspondem às velocidades nos Pontos 1 (campo aberto), 2 (antes da barreira) e 3 (depois da barreira). Os valores dos Pontos 2 e 3 foram corrigidos conforme já esclarecido.

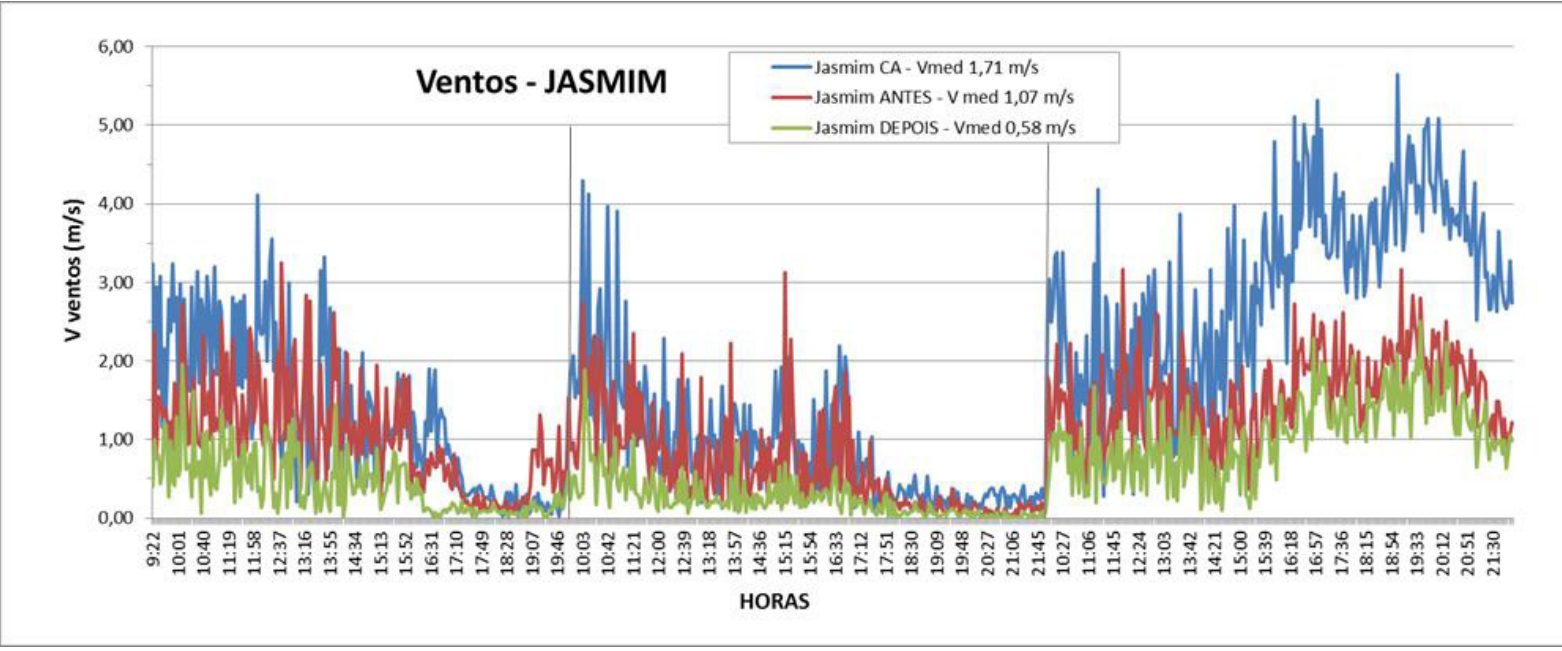

Figura 10 - Ventos - JASMIM - Pontos 1 a 3 - Dias 06, 07 e 08 ago. 2014 


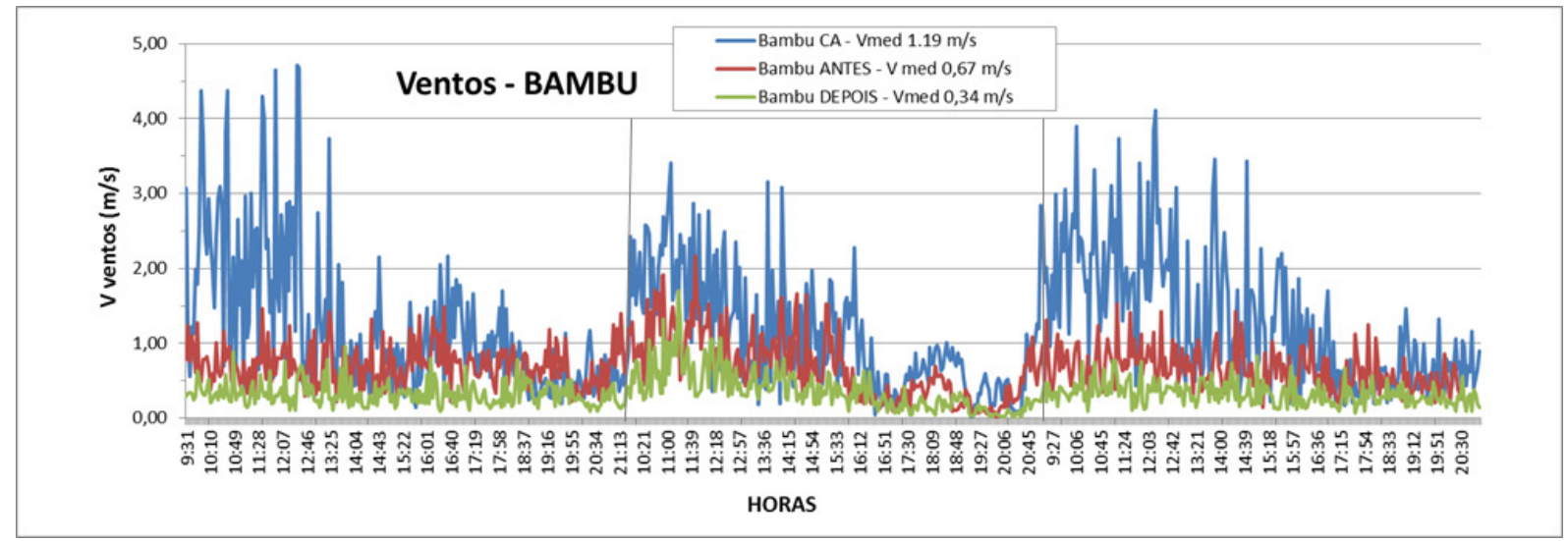

Figura 11 - Ventos - BAMBU - Pontos 1 a 3 - Dias 09, 11 e 15 ago. 2014

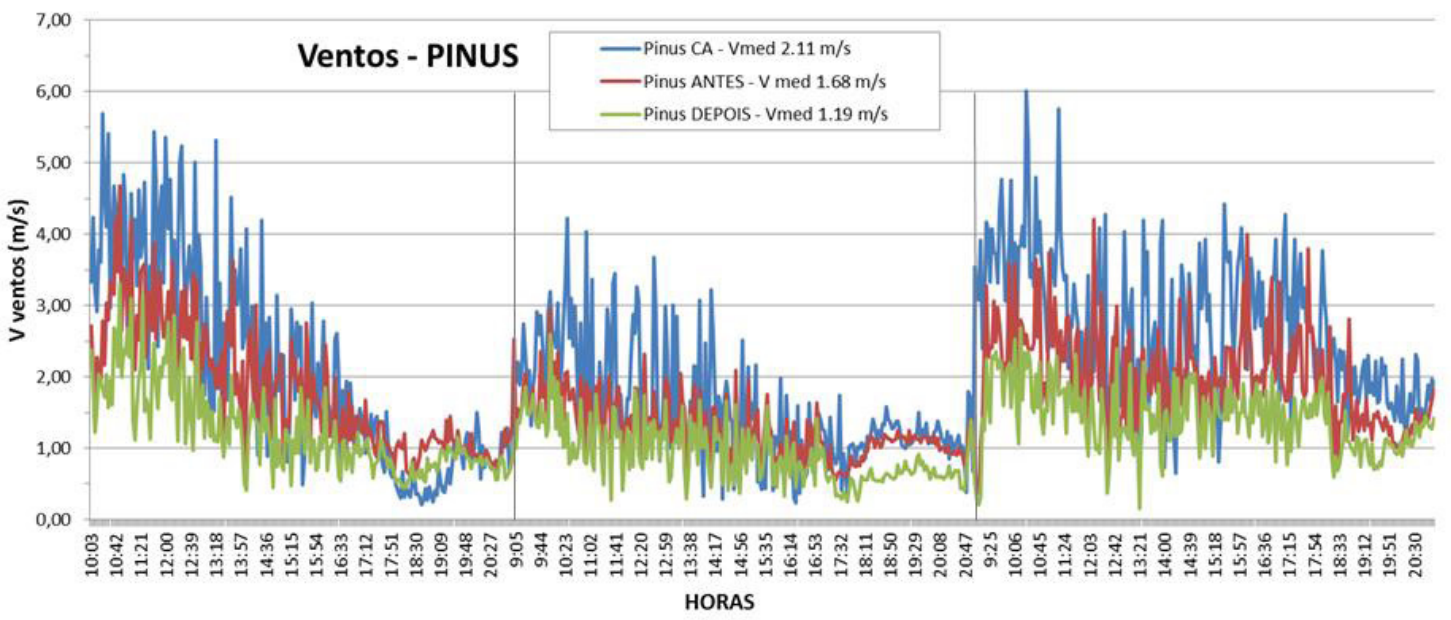

Figura 12 - Ventos - PINUS - Pontos 1 a 3 - Dias 06, 08 e 09 set. 2014

Pode-se observar que os valores medidos em campo aberto apresentam picos bem mais acentuados que os valores medidos próximos às barreiras. Para melhor visualização da influência das barreiras vegetais, nas Figuras 13 a 15 estão retratados apenas os ventos registrados nos Pontos 2 (antes da barreira) e 3 (depois da barreira).

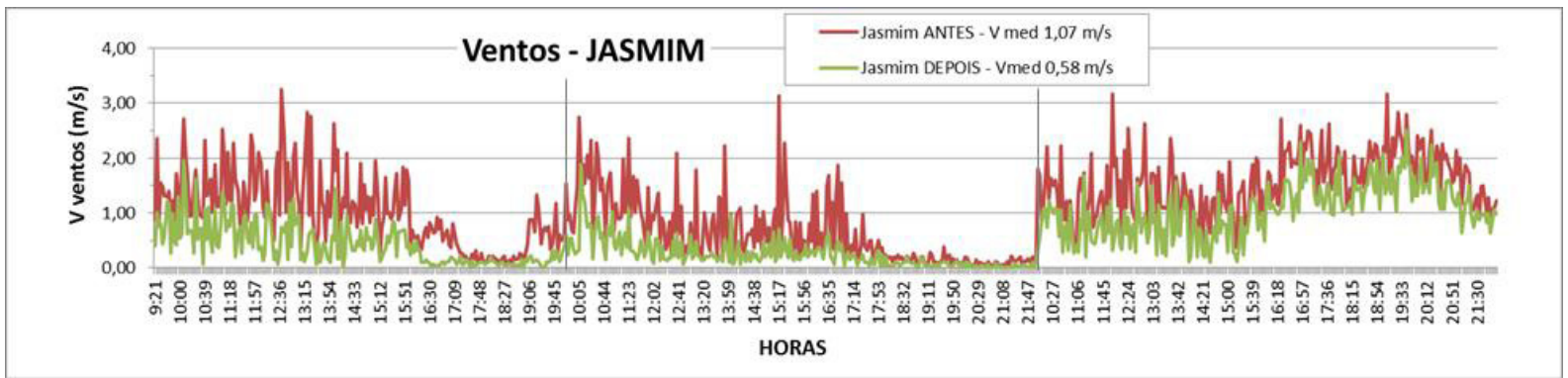

Figura 13 - Ventos - JASMIM - Pontos 2 e 3 - Dias 06, 07 e 08 ago. 2014 


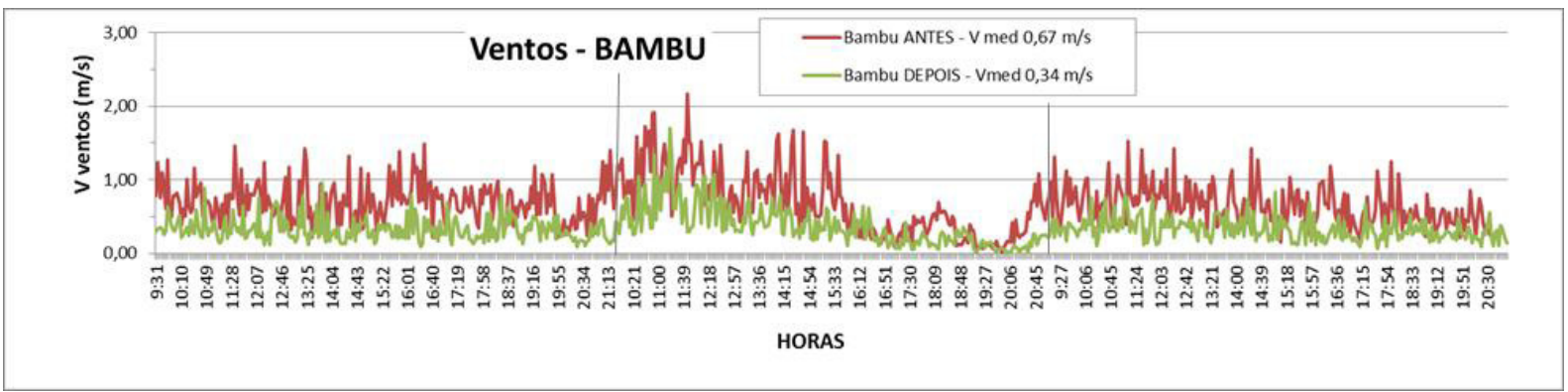

Figura 14 - Ventos - BAMBU - Pontos 2 e 3 - Dias 09, 11 e 15 ago. 2014

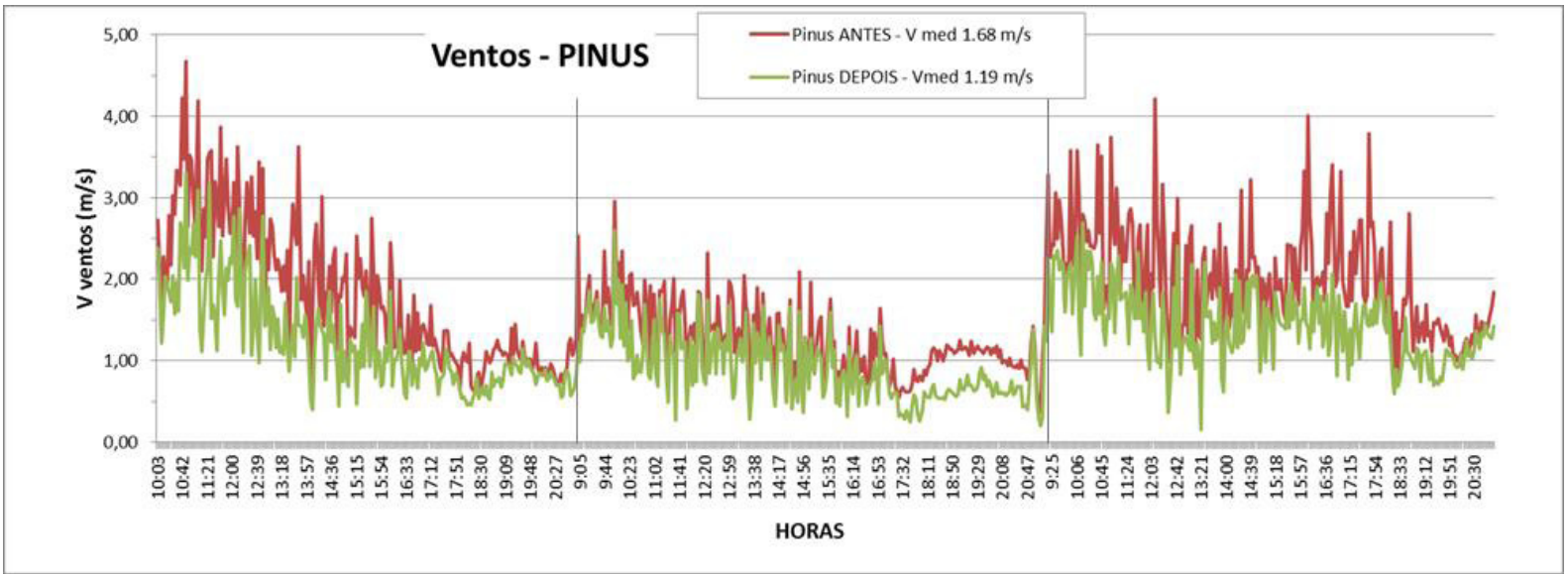

Figura 15 - Ventos - PINUS - Pontos 2 e 3 - Dias 06, 08 e 09 set. 2014

Os ventos medidos no Pinus são mais intensos; as diferenças mais perceptíveis estão entre o Bambu e o Pinus, tanto na intensidade dos ventos quanto nas diferenças entre as medições antes e depois da barreira, indicando novamente a maior eficiência do Bambu na barragem dos ventos.

Os valores de LAl medidos nos 3 elementos vegetais estudados apresentaram os seguintes resultados:

Tabela 4 - Valores de LAI resultantes a partir de 3 medições por espécie, com 10 repetições por medição

\begin{tabular}{llllll}
\hline Nome comum & LAl $\mathbf{1}$ & LAl 2 & LAl 3 & Média & Desvio Padrão \\
\hline Pinus & 3,44 & 3,78 & 4,32 & 3,8 & 0,44 \\
Jasmim & 5,21 & 5,16 & 4,91 & 5,1 & 0,16 \\
Bambu & 5,96 & 5,95 & 5,96 & 6,0 & 0,01 \\
\hline
\end{tabular}




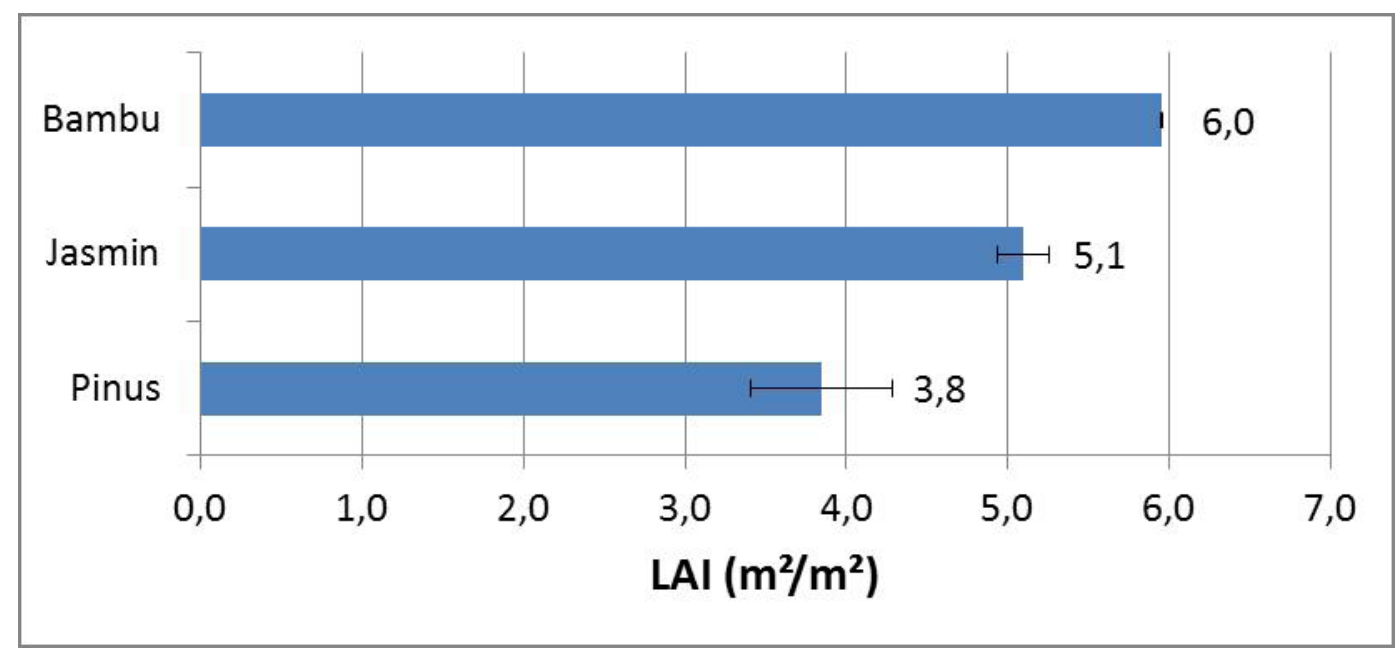

Figura 16 - Valores de LAI resultantes

Os dados de LAI medidos foram comparados aos valores de atenuação da velocidade do vento nas 3 vegetações. Os resultados foram obtidos com a aplicação do software Minitab versão 17. A Tabela 6 apresenta os resultados das medições em campo, nas relações entre os Pontos 2 e 3 por vegetação, para avaliar o desempenho que apresentaram como barreira aos ventos.

Tabela 5 - Ventos resultantes entre os Pontos 2 e 3 x LAI por vegetação

\begin{tabular}{|c|c|c|c|c|c|}
\hline $\begin{array}{l}\text { Rótulos de } \\
\text { Linha }\end{array}$ & $\begin{array}{c}\text { Média de } \\
\text { VENTO }(\mathrm{m} / \mathrm{s})\end{array}$ & $\begin{array}{c}\text { Var. de VENTO } \\
(\mathrm{m} / \mathrm{s})\end{array}$ & $\begin{array}{l}\text { Desv. Pad. de } \\
\text { VENTO }(\mathrm{m} / \mathrm{s})\end{array}$ & $\begin{array}{c}\text { Soma de } \\
\text { VENTO (\%) }\end{array}$ & LAI \\
\hline BAMBU & 0,51 & 0,11 & 0,33 & & 5,96 \\
\hline Ponto 2 & 0,67 & 0,11 & 0,34 & & \\
\hline Ponto 3 & 0,34 & 0,04 & 0,21 & $-49,29 \%$ & \\
\hline JASMIM & 0,82 & 0,46 & 0,67 & & 5,09 \\
\hline Ponto 2 & 1,07 & 0,52 & 0,72 & & \\
\hline Ponto 3 & 0,58 & 0,27 & 0,52 & $-45,78 \%$ & \\
\hline PINUS & 1,43 & 0,49 & 0,70 & & 3,85 \\
\hline Ponto 2 & 1,68 & 0,57 & 0,75 & & \\
\hline Ponto 3 & 1,19 & 0,29 & 0,54 & $-29,10 \%$ & \\
\hline Total geral & 0,92 & 0,50 & 0,70 & & \\
\hline
\end{tabular}

(a) Soma de vento $=\%$ de redução da velocidade do vento entre os Pontos 2 (antes) e 3 (após a barreira), por vegetação, em função de um valor incidente de $100 \%$ 
Os valores do item Soma de Vento da Tabela 5 foram relacionados com os valores de LAI medidos por planta conforme Figura 17.

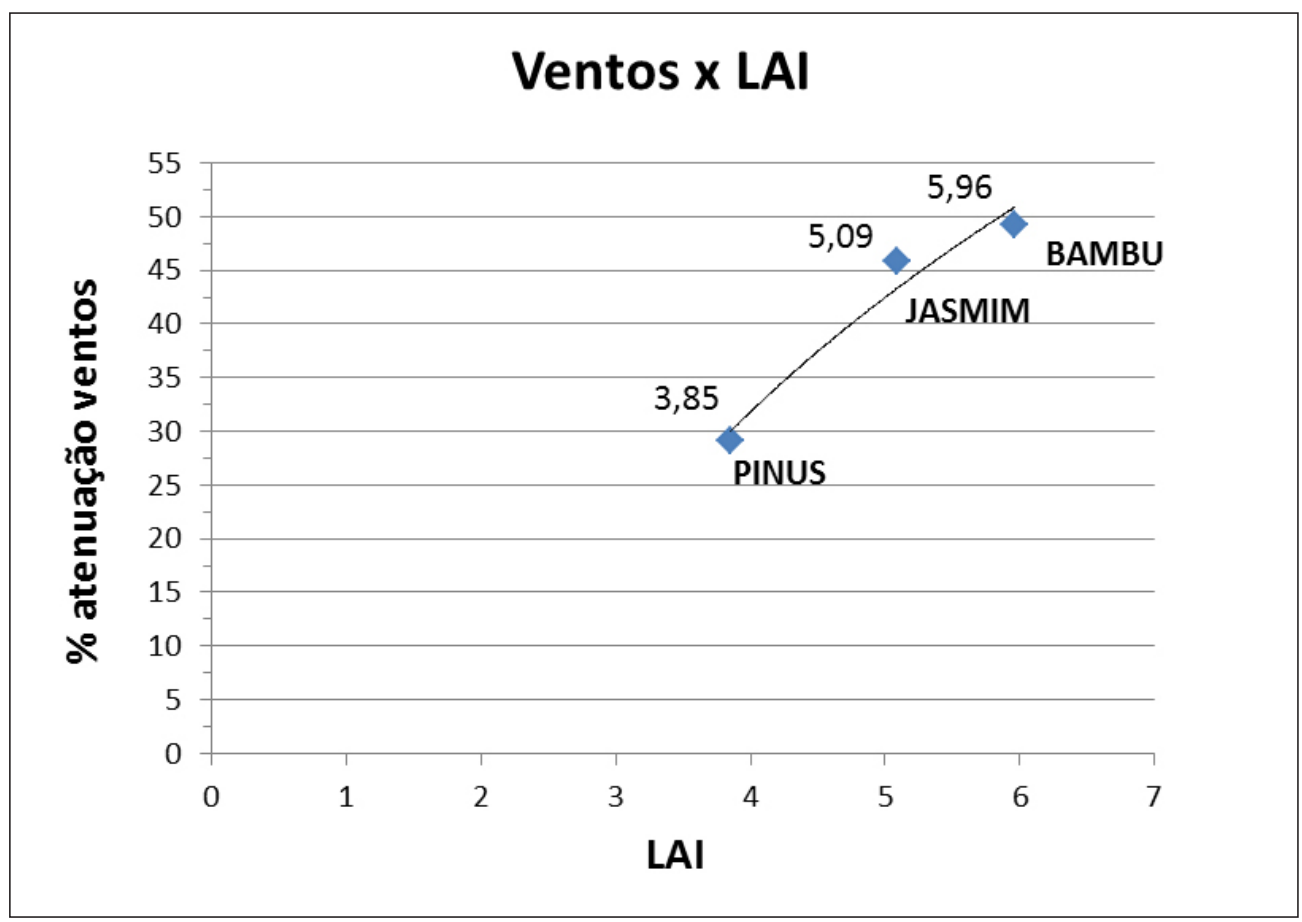

Figura 17 - Gráfico de Tendência - LAI x \% de atenuação dos ventos

A tendência verificada no gráfico acima mostra-se compatível com a viabilidade de adoção do LAl como parâmetro para desempenho de elementos vegetais como barreira aos ventos.

\section{CONCLUSÕES}

É de conhecimento geral que estudos que envolvem medição de ventos são complexos, uma vez que sua variabilidade é instantânea e depende de múltiplos fatores. No entanto faz-se necessário elaborar estudos constantes a respeito, para buscar parâmetros que auxiliem projetistas e outros profissionais que dele dependam para desenvolver suas atividades.

Em relação aos objetivos propostos, pode-se dizer que a abordagem do tema, as pesquisas e as medições efetuadas foram úteis para conceber uma visão inicial a respeito da relação entre vegetação de barreira aos ventos e os índices avaliados. Foi possível 
quantificar a atenuação dos ventos pelos três arranjos de vegetação propostos e a correspondência entre seus resultados.

Estes resultados mostraram evidências de que a busca da correlação entre o LAl e o desempenho da vegetação como barreira aos ventos é um caminho promissor para pesquisas e estudos mais aprofundados; o método não pôde ser conclusivo por ausência de intensidade amostral. Na medida em que o tema estudado seja desenvolvido, novas contribuições serão obtidas para aplicação de melhorias no planejamento urbano de praças, parques e outros espaços urbanos abertos. A silvicultura urbana seria beneficiada com maior exploração de estudos dessa natureza.

É importante ressaltar que para quantidades amostrais mais significativas faz-se necessário a obtenção de mais equipamentos de medição, especialmente anemômetros, para permitir a medição simultânea em uma quantidade maior de pontos, além das importantes repetições. $O$ banco de dados da ESALQ já contém um grande número de resultados de LAI para espécies vegetais, medidos in loco; esses dados poderiam ser explorados em estudos futuros associados a barreiras arbóreas.

\section{REFERÊNCIAS BIBLIOGRÁFICAS}

ALI-TOUDERT, F.; MAYER, H. Effects of asymmetry, galleries, overhanging façades and vegetation on thermal comfort in urban street canyons. Solar Energy, Freiburg, v. 81, p. 742-754, 2007.

ASSIS, E.S.; SIRQUEIRA, C.A.; BAMBERG, A.M. Influência da vegetação no microclima em ambiente simulado controlado. In: ENCONTRO NACIONAL DE CONFORTO NO AMBIENTE CONSTRUÍDO, 12.; ENCONTRO LATINOAMERICANO DE CONFORTO NO AMBIENTE CONSTRUÍDO, 8., 2013, Brasília. Anais... Brasília: ENCAC, 2013. p. 324-338.

BARRETtO, A. G. O. P.; SPAROVEK, G.; GIANNOTTI, M. Atlas Rural de Piracicaba. Piracicaba: Instituto de Pesquisas e Estudos Florestais - IPEF, 2006, 76 p.

BITOG, J.P.; LEE, I.-B.; HWANG, H.-S.; SHIN, M.-H.; HONG, S.-W.; SEO, I.-H.; KWON, K.-S.; MOSTAFA, E.; PANG, Z. Numerical simulation study of a tree windbreak. Biosystems Engineering, Seoul, v. 3, p. 40-48, 2012. 
BLOCKEN, B.; JANSSEN, T.; VAN HOOFF, T. CFD simulation for pedestrian wind comfort and wind safety in urban areas: general decision framework and case study for the Eindhoven University campus. Environmental Modelling \& Software, Eindhoven, v. 30, p. 15-34, 2012.

BONAN, G. Ecological climatology: concepts and applications. Cambridge: Cambridge University Press, 2002, 690 p.

BOTTILLO, S.; VOLLARO, A.D.L.; GALLI, G.; VALLATI, A. CFD modeling of the impact of solar radiation in a tridimensional urban canyon at different wind conditions. Solar Energy, Rome, v. 102, p. 212-222, 2014.

BOURDIN, P.; WILSON, J.D. Windbreak aerodynamics: is computational fluid dynamics reliable? Boundary-Layer Meteorology, Edmonton, v. 126, n. 2, p. 181-208, 2007.

BROWN, R.D.; GILLESPIE, T.J. Microclimatic landscape design: creating thermal comfort and energy efficiency. New York: John Wiley, 1995.193 p.

CHEN, L.; NG, E. Outdoor thermal comfort and outdoor activities: a review of research in the past decade. Cities, Hong Kong, v. 29, p. 118-125, 2012.

CHU, C.-R.; CHANG,C.-Y.; HUANG, C.-J.; WU, T.-R.; WANG, C.-Y.; LIU, M.-Y. Windbreak protection for road vehicles against crosswind. Journal of Wind Engineering and Industrial Aerodynamics, Taiwan, v. 116, p. 61-69, 2013.

DOBBERT, L.Y. Arborização na cidade de Campinas/SP: percepção e conforto. Tese (Doutorado em Recursos Florestais) - Escola Superior de Agricultura "Luiz de Queiroz", Universidade de São Paulo, Piracicaba, 2014.

DONG, Z.; LUO, W.; QIAN, G.; LU, P.; WANG, H. A wind tunnel simulation of the turbulence fields behind upright porous wind fences. Journal of Arid Environments, Lanzhou, v. 74, p. 193-207, 2010.

ERELL, E.; PEARLMUTTER, D.; WILLIAMSON, T. Urban microclimate: designing the spaces between buildings. London: MPG Books, 2011. 266 p.

FAHMY, M.; SHARPLES, S.; YAHIYA, M. LAI based trees selection for mid latitude urban developments: a microclimatic study in Cairo, Egypt. Building and Environment, Cairo, v. 45, p. 345-357, 2010. 
FROTA, A.B.; SCHIFFER, S.R. Manual de conforto térmico: arquitetura, urbanismo. 5. ed. São Paulo: Studio Nobel, 2001. 243 p.

GAO, Y.; YAO, R.; LI, B.; TURKBEYLER, E.; LUO,Q.; SHORT, A. Field studies on the effect of built forms on urban wind environments. Renewable Energy, Cambridge, v. 46, p. 148-154, 2012.

GEIGER, R. Manual de climatologia: o clima da camada de ar junto ao solo. Lisboa: Fundação Calouste Gulbenkian, 1960. 556 p.

INSTITUTO BRASILEIRO DE GEOGRAFIA E ESTATÍSTICA. Censo 2010. Disponível em: <ftp://ftp.ibge.gov.br/Censos/Censo_Demografico_2010/Resultados_do_Universo/ tabelas_pdf/tab1.pdf>. Acesso em: 19 maio 2015.

JONES, H. Plants and microclimate: a quantitative approach to environmental plant physiology. $2^{\text {nd }}$ ed. Cambridge: Cambridge University Press, 1992. 428 p.

JUNG, W.-S.; PARK, J.-K.; LEE, H.-W.; KIM, E.-B.; CHOI, H.-J. Wind speed variation over the leeward region according to vegetation under the strong wind. In: INTERNATIONAL CONFERENCE WIND EFFECTS ON TREES, 2., 2009, Freiburg. Proceedings... Freiburg: Univ. Freiburg, Ber. Meteor. Inst., 2009. p. 255-261.

KOENIGSBERGER, O.H.; INGERSOLL, T.G.; MAYHEW, A.; SZOKOLAY, S.V. Viviendas y edificios en zonas cálidas y tropicales. London; Madrid: Paraninfo, 1977. 328 p.

KUHNS, M. Planting trees for energy conservation: the right tree in the right place. Utah State of University, 2008. Disponível em: <http://forestry.usu.edu/htm/city-andtown/tree-selection/planting-trees-for-energy-conservation-the-right-tree-in-the-rightplace>. Acesso em: 28 maio 2015.

LEE, K.H.; EHSANI, R.; CASTLE, W.S. A laser scanning system for estimating wind velocity reduction through tree windbreaks. Computers and Electronics in Agriculture, Florida, v. 73, p. 1-6, 2010.

LOMBARDO, M.; BIAS, E.S.; BAPTISTA, G.M.M. Análise do fenômeno de ilhas de calor urbanas, por meio da combinação de dados Landsat e Ikonos. In: SIMPÓSIO BRASILEIRO DE SENSORIAMENTO REMOTO, 11, 2003, Belo Horizonte. Anais... São José dos Campos: INPE, 2003. p. 1741-1748. 
LOPES, A.; VASCONCELOS, J. A influência da morfologia urbana na modificação das brisas do estuário do Tejo na zona oriental de Lisboa. Lisboa: Universidade de Lisboa, Faculdade de Letras, Centro de Estudos Geográficos, 2007. 360 p.

MASCARÓ, L.R. de. Ambiência urbana. 2. ed. Porto Alegre: +4 Editora, 2004. 199 p.

MOCHIDA, A.; LUN. I.Y.F. Prediction of wind environment and thermal comfort at pedestrian level in urban area. Journal of Wind Engineering and Industrial Aerodynamics, Sendai, v. 96, p. 1498-1527, 2008.

MONTEIRO, C.A.F.; MENDONÇA, F. Clima urbano. São Paulo: Contexto, 2003. 192 p.

MONTEIRO, E.Z. Verdes-dentro e verdes-fora: visões prospectivas para espaços abertos urbanos - privados e públicos - em área habitacional de interesse social. 2007. 272 p. Tese (Doutorado em Arquitetura e Construção) - Faculdade de Engenharia Civil, Universidade Estadual de Campinas, Campinas, 2007.

MONTEIRO, L.M. Modelos preditivos de conforto térmico: quantificação de relações entre variáveis microclimáticas e de sensação térmica para avaliação e projeto de espaços abertos. 2008. 379 p. Tese (Doutorado em Tecnologia da Arquitetura) Faculdade de Arquitetura e Urbanismo, Universidade de São Paulo, São Paulo, 2008.

MONTEIRO, L.M.; DUARTE, D.; GONÇALVES, J.S.; ALUCCI, M.P. Conforto térmico como condicionante do projeto arquitetônico-paisagístico: o caso dos espaços abertos do novo centro de pesquisas da Petrobras no Rio de Janeiro, CENPES II. Associação Nacional de Tecnologia do Ambiente Construído, Porto Alegre, v. 8, n. 4, p. 61-86, 2008.

NIKOLOPOULOU, M. Designing open spaces in the urban environment: a bioclimatic approach; RUROS: Rediscovering the Urban Realm and Open Spaces. Greece: Centre for Energy Resources, Department of Buildings, 2004. 53 p.

OKE, T.R. Boundary layer climates. $2^{\text {nd }}$ ed. London; New York: Routledge; John Wiley, 1987. $435 \mathrm{p}$.

Initial guidance to obtain representative meteorological observations at urban sites. Vancouver: World Meteorological Organization, 2006. 47 p. (Instruments and Observing Methods, Report, 81; WMO/TD, 1250). 
OLGYAY, V.; OLGYAY, A. Design with climate: bioclimatic approach to architectural regionalism. New Jersey: Princeton University Press, 1963. 190 p.

OMETTO, J.C. Bioclimatologia vegetal. São Paulo: Agronômica Ceres, 1981. 440 p.

PARK, M.; HAGISHIMA, A.; TANIMOTO, J.; NARITA, K. Effect of urban vegetation on outdoor thermal environment: field measurement at a scale model site. Building and Environment, Fukuoka, v. 56, p. 38-46, 2012.

PENWARDEN, A.D. Acceptable wind speeds in towns. Building Science, London, v. 8, p. 259-267, 1973.

PENWARDEN, A.D.; WISE, A.F.E. Wind environment around buildings. London: Department of the Environment BRE, Her Majesty's Stationery Office, 1975. 52 p.

PRATA, A.R. Dimensionamento do impacto da altura de edifícios nas condições de ventilação natural do meio urbano simulando em túnel de vento: o caso de Santos. 2005. 243 p. Tese (Doutorado em Arquitetura e Urbanismo) -Faculdade de Arquitetura e Urbanismo, Universidade de São Paulo, São Paulo, 2005.

RIVERO, R. Arquitetura e clima: acondicionamento térmico natural. 2. ed. Porto Alegre: D.C. Luzzatto Editores, 1986. 240 p.

SANTAMOURIS, M. Environmental design of urban buildings: an integrated approach. London: Sterling, 2006. 322 p.

SANTIAGO, J.L.; MARTÍN, F.; CUERVA, A.; BEZDENEJNYKH, N.; SANZ-ANDRÉS, A. Experimental and numerical study of wind flow behind windbreaks. Atmospheric Environment, Madrid, v. 41, p. 6406-6420, 2007.

SARAIVA, J.A.G. Ação do vento e nível de conforto em espaços urbanos. In: ENCONTRO DE PROFESSORES DE CONFORTO AMBIENTAL, 2.; CICLO DE PALESTRAS DE CONFORTO AMBIENTAL E CONSERVAÇÃO DE ENERGIA, 2., 1994, João Pessoa. Anais... João Pessoa: UFPB, 1994. p. 23-31.

SHASHUA-BAR, L.; HOFFMAN, M.E. Vegetation as a climatic component in the design of an urban street An empirical model for predicting the cooling effect of urban green areas with trees. Energy and Buildings, Haifa, v. 31, p. 221-235, 2000. 
SILVA FILHO, D.F. da; PIVETTA, K.F.L.; COUTO, H.T.Z.; POLIZEL, J.L. Indicadores da floresta urbana a partir de imagens aéreas multiespectrais de alta resolução. Scientia Forestalis, Piracicaba, n. 67, p. 88-100, 2005.

SIMÕES, J.W.; DURIGAN, G. Quebra-ventos de Grevillea robusta A. CUNN: efeitos sobre a velocidade do vento, umidade do solo e produção do café. IPEF, Piracicaba, n. 36, p. 27-34, 1987.

STATHOPOULOS, T. Pedestrian level winds and outdoor human comfort. Journal of Wind Engineering and Industrial Aerodynamics, Montreal, v. 94, p. 769-780, 2006.

SZÜCS, A. Wind comfort in a public urban space: case study within Dublin Docklands. Frontiers of Architectural Research, Dublin, v. 2, p. 50-66, 2013.

WATSON, D.J. Comparative physiological studies in the growth of field crops. I. Variation in net assimilation rate and leaf area between species and varieties, and within and between years. Annals of Botany, London, v. 11, p. 41-76, 1947.

WONG, N.H.; CHEN, Y. Tropical urban heat islands: climate, buildings and greenery. London; New York: Taylor \& Francis, 2009. 259 p.

WU, H.; KRIKSIC, F. Designing for pedestrian comfort in response to local climate. Journal of Wind Engineering and Industrial Aerodynamics, Guelph, v. 104/106, p. 397-407, 2012.

WU, X.; ZOU, X.; ZHANG, C.; WANG, R.; ZHAO, J.; ZHANG, J. The effect of wind barriers on airflow in a wind tunnel. Journal of Arid Environments, Beijing, v. 97, p. 73-83, 2013.

YEH, C.-P.; TSAI, C.-H.; YANG, R.-J. An investigation into the sheltering performance of porous windbreaks under various wind directions. Journal of Wind Engineering and Industrial Aerodynamics, Tainan, v. 98, p. 520-532, 2010. 